\title{
Improvement in Delay of Information flow in Energy Efficiency Organization
}

\author{
Elham Hasanzadeh $^{1}$ and Reza Askari moghadam ${ }^{2}$ \\ ${ }^{1}$ PAYAM NOOR University faculty of engineering, Tehran, Iran \\ hasanzadehesaba.org.ir \\ ${ }^{11}$ PAYAM NOOR University faculty of engineering, Tehran, Iran \\ askariepnu.ac.ir
}

\begin{abstract}
One of the most important issues in task organization is service speed and reduction of delays. High speed in tasks and reduction of delay cause high performance in task organization. So many studies have done in this field. Some of these studies during the past ten years are redesigning tasks in information process, using the simulation product development, designing and manufacturing managing supply chain, and FINC methodology which has been used in military of American and Australia.

In this article FINC methodology is modified for a business organization. The proposed method applied on information flows of current situation of Iran energy efficiency organization. Mind manager software is used for viewing it by social network analysis and then FINC methodology for calculation of delay rate on it. Sum of delay rate with delays in decision nodes was added and then improved.
\end{abstract}

\section{KEYWORDS}

Business organization, Delay reduction, FINC methodology

\section{INTRODUCTION}

One of the most important issues in task organization is service speed and reduction of delays. The delays cause procrastination in projects and services which itself is the source of many problems including losing customers.

There are numbers of studies and related works for delay reduction, which are discussed here briefly.

One of the measures done for reducing delays is redesigning tasks in information process; i.e. redesigning can be used to optimize information flow, consolidation of some tasks in one has been effective. In this approach, one or more unit's tasks are assigned to a unit so one person is responsible for them. This can omit the delay caused by information transferring among the units, so a task which should be done in first unit and then transferred to another, is done in one unit. However, notice the point such as project control in units' consolidation, and lack of skill for the consolidated tasks. Another delay is related to task hand-off, and the last one is consolidation cost. All of the points should be studied so the project cost after the consolidation is not higher than before. [1]

Another approach to reduce the delays in an organization is using simulation product development, designing and manufacturing. This concept is used more in competitive companies, since in these companies being the first is important. In this approach the base is early optimizing of concept/architecture phase, i.e. the optimization should be done during the designing and architecture not the production. Here, for the competition improvement, there is a need for changing from serial designing to concurrent engineering; so that the tasks can be done in parallel and with more speed, e.g. manufacturing companies in which first designing phase and then control and test are done. If the test and control are done after the designing phase in serial 
approach, and then a problem shows up, there will be a need for redesigning, which will increase the cost and delay. [2]

Another approach is managing supply chain which means cooperation between units in a chain. In many cases a tiny problem in a supply chain can reduce organization efficiency. This may have different sources, and affect individual decision making. The approach used here is simulation which utilizes Extend TM software. The simulation offers an effective method for modelling the chain output in heterogeneous behaviours. In simulation, values changes to outputs which show, in a manufacturing organization, missing sales increases by time delay. RFID is used to increase the information transferring for viewing stocks and decrease damages in information. [3]

The other approach which is offered for health care centers is improving Emergency Department (ED). There may be purely financial "business case" for investments that improve ED throughput and reduce delays. That is, there may be system-wide saving associated with investments targeted to improving ED throughput. Researches show that factors external to the ED, such as hospital bed availability, laboratory turnaround, specialist consultation availability and elective surgery schedules may be more important in determining ED throughput than internal bottlenecks such as ED staff availability and bed shortages. The figures suggest that

There may be a business case for interventions that improve ED flow and reduce admission delay. [4]

Another approach to reduce the time delays is using FINC methodology. This methodology is designed mostly for reducing Delay rate in military in C4ISR (Command, Control, Communications, Computers, Intelligence, Surveillance, Reconnaissance) architecture by Dekker. This methodology uses the information coefficient, the coordination coefficient and the intelligence coefficient. It utilizes graphs to show organization stocks, and sources of time delay. Current situation is studied using this methodology so the certain parts cause delay and reason of that will be found.

In this article we want to change the application of FINC methodology and use this methodology in business organizations. We are going to find that if we can use this methodology for business organization? And whether it can reduce delay rate in business organizations or not?

We selected Iran Energy Efficiency Organization as a business organization and consider current situation on it and try to reduce delay rate using FINC methodology. [11]

\section{Social Network Analysis}

Social network analysis is used in many fields such as organizational behaviors, anthropology, sociology, medicine, biology, communication studies, economics, geography... [5, 6]

A social network analysis (SNA) examines the structure of social relationships in a group to uncover the informal connections between people. In a consulting setting, these relationships are often ones' communication, awareness, trust, and decision-making.

Most recently, SNA has become an important tool for organizational consultants seeking to understand the connection between patterns of interactions and business outcomes such as job performance, job satisfaction, adoption of new ideas or technologies, likelihood of information getting shared, and creation of new ideas.

Studding on social network analysis helps us to consider where collaboration is breaking down, where talent and expertise could be better leveraged, where decisions are getting bogged down, and where opportunities for diffusion and innovation are being lost. With theses information we can change the roles and forbiddances to foster more effective patterns of communication, improve reliability, use of technology so that it is more reachable for others, re-alignment of rewards and incentive programs. [7]

The goals of social network analysis are visualise the relationship, study the factors which influence relationships and draw out implications of the relational data. [9] 
2.1. Relations in social network analysis $[7,8]$

Strong and weak: Strong ties indicate a relation with a higher number, more communication, and feeling of closeness. Weak ties may offer more social support, but since they can be preserved easily, you can have lots of them. They are more important than the strong ones. Weak relations are important for innovations. Creating balance between these two is really essential for business.

One-way and Two-way relations: A one-way relation is a relation between two nodes that goes from the first node to the second node but it doesn't go back. A two-way relation is a relation between two nodes that goes from the first node to the second node and back to the first node from the second node.

Direct or indirect relations: An indirect relation is between two people, for example I send a letter to you, and this is a direct relation. An indirect relation is a relation from a person to another person which passes through one or more intermediates. For example, I send a gift to you but I give it to a middleman to bring it to you. The middleman is an intermediate and the relation between you and I, is an indirect one. Intermediates are very important in a network.

\section{FINC Methodology}

FINC methodology is used for C4ISR architectures and network centric warfare (NCW). The term C4ISR architectures is used by the US and other militaries to refer to the organizational structure used by military forces for carrying out a mission. [10]

The FINC (Force, Intelligence, Networking, and C2) methodology analyses NCW or C4ISR architectures in terms of:

Force nodes, which conduct activities $(\mathrm{F})$;

Intelligence or information-generating nodes (I);

Network links $(\mathrm{N})$; and

C2 nodes (C) [11]

Figure 1 illustrates an example (discussed in more detail in the body of the paper). C2 nodes are indicated by circles, Intelligence nodes by rounded boxes, and Force nodes by square boxes (Force nodes can also generate information, as well as carrying out activities). Network links provide communication between nodes, indicated by lines or arrows in Figure 1, depending on whether information flow is bidirectional or unidirectional. [11].

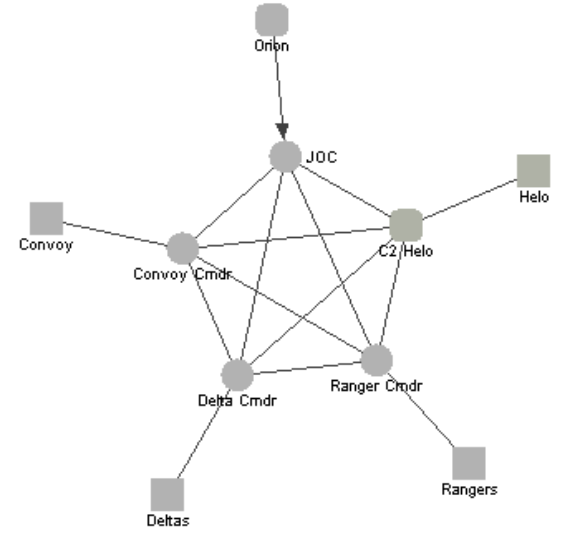

Figure1. Simplified architecture for Mogadishu scenario. [9]

With FINC methodology we can calculate three metrics or coefficient for every C4ISR: the information flow coefficient, the coordination coefficient, and the intelligence coefficient. The FINC intelligence coefficient alone is able to predict $95 \%$ of the variance in performance. [12] 
We briefly explain the example "Black Hawk Down" [11]. We consider that current situation and use intelligence coefficient for improving delay rate on it. In this example, there are many units that do work like special forces operational detachment-Delta, elements of 72 Ranger regiment, element of 160 special operations ... and some of diction units like JOC and ORION aircraft. For each connection, in FINC methodology, a technology rating has been given based on table 1 .

Table1. Technology ratings used with the FINC metrics. [11]

\begin{tabular}{|l|l|}
\hline Rating & Technology \\
\hline Level 1 & Face-to-face contact \\
\hline Level 2 & Video-conferencing, or voice plus video feed \\
\hline Level 3 & Voice plus limited data feed \\
\hline Level 4 & Plain voice, or rich email \\
\hline Level 5 & Plain text email, or limited data feed \\
\hline
\end{tabular}

And for each connection has given an Organizational Interoperability Model (OMI) based on table2.

Table2. The Organizational Interoperability Model (OIM) adapted to use with the FINC metrics.

\begin{tabular}{|c|c|c|c|}
\hline $\begin{array}{c}\text { Level 4 } \\
\text { Unified }\end{array}$ & $\begin{array}{c}\text { Preparedness } \\
\text { Normal day-to-day } \\
\text { working }\end{array}$ & Command style & Ethos \\
\hline $\begin{array}{c}\text { Level3 } \\
\text { Combined }\end{array}$ & $\begin{array}{c}\text { Detailed doctrine } \\
\text { and experience in } \\
\text { using it }\end{array}$ & $\begin{array}{c}\text { One chain of command and } \\
\text { interaction with home } \\
\text { organisation }\end{array}$ & $\begin{array}{c}\text { Shared ethos but with } \\
\text { influence from home } \\
\text { organisation }\end{array}$ \\
\hline $\begin{array}{c}\text { Level2 } \\
\text { Collaborative }\end{array}$ & $\begin{array}{c}\text { General doctrine in } \\
\text { place and some } \\
\text { experience }\end{array}$ & $\begin{array}{c}\text { Separate reporting lines of } \\
\text { responsibility overlaid with } \\
\text { a single command chain }\end{array}$ & $\begin{array}{c}\text { Shared purpose: goals, } \\
\text { value, system } \\
\text { significantly influenced } \\
\text { by home organisation }\end{array}$ \\
\hline $\begin{array}{c}\text { Level 1 } \\
\text { Ad hoc }\end{array}$ & General Guidelines & $\begin{array}{c}\text { Separate reporting lines of } \\
\text { responsibility }\end{array}$ & Shared purpose \\
\hline $\begin{array}{c}\text { Level0 } \\
\text { Independent }\end{array}$ & No preparedness & No interactions & Limited shared purpose \\
\hline
\end{tabular}

For each link, we obtain an overall "delay" factor, which estimates the combined effect of organizational and technical obstacles to effective information flow:

Delay $=(5-$ OIM $) \times$ technical [11]

We, then, calculate the intelligence coefficient by considering each combination of an information source and a force node which might use the information, and add up the quality / delay ratios for each such combination. [11]

\section{Calculate delay of information flows in Iran efficiency Organization}

In this section the analytical social nets are investigated using FINC in Power Plant section of IRAN Energy Efficiency Organization. First the projects' data process were illustrated using Mind Manger software. Its base was FINC methodology. The circles show the decision making sections as intelligence nodes in the organization, and rectangular illustrate executive sections as Force nodes. Some decision making sections are also responsible for collecting information. The 
connections show the data movement procedure; here mutual relations are drawn separately. Figure 2 shows these graphs.

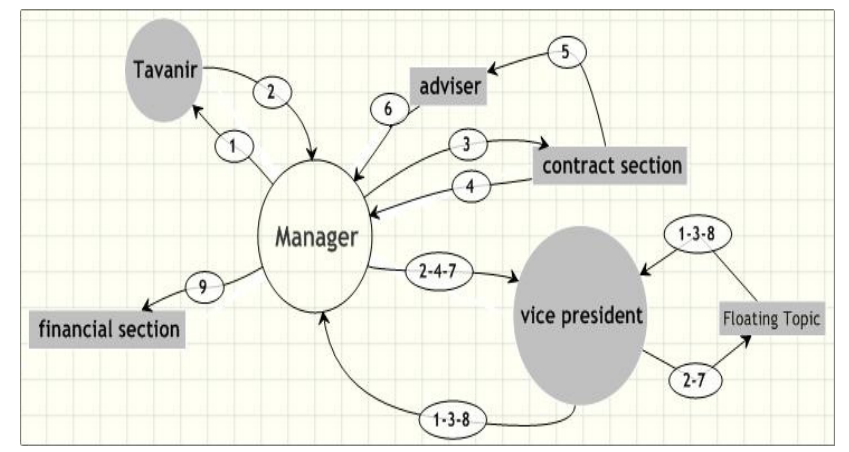

Figure 2: Illustrating powerhouse data process using Mind Manager Software

Delay topography and estimating these delays are studied based on decision making nodes and number of relations. First, the data procedures were recognized and two delays estimated for each. For this part, two data procedures were considered including: performing the project from beginning to the end and financial affairs. In this project, an agreement should be received from TAVANIR $^{1}$ organization firm, and then a counsellor is chosen for this process.

Data procedure includes crests with nodes from 1 to 9. 1) Provide the agreement, 2) Receive confirmation, 3) Request for choosing an adviser, 4) Contract, 5) Assign the adviser, 6) Send activities report, 7) Receive group confirmation, 8) Final confirmation, 9) Financial payment.

The first data procedure includes 1 to 5 nodes and the second one includes 6 to 9 . Defining the crests or data procedures sides, now is turn to finding delay reasons and numerical estimation. Here, total delay is equal to total delays caused by decision makers $(\mathrm{C} 2)$ and delays caused by relations. Decision makers delay is estimated based on decision making times by decision makers such as the manager and vicars( here the data procedures from the manager is ignored due to the long time it takes) and relation delay is based on data hierarchy movement.

For the first data procedure the decision makers delay was 3 and relation delay was 10 so the total delay would be 13, for the second data procedure the former was 2 and the later was 7 so the total would be 9 .

Delay $=$ number of decision nodes + number of relations

Data procedure $1=3+10=13$

Data procedure $2=2+7=9$

After the delay estimation now is time for improvement of these procedures. The solution is authorizing the section vector for some affairs but yet they follow the rules and reporte the process to the manager. So, now, the total delay for data procedure 1 would reduce to 7 and data procedure 2 would reduce to 5 which are significant. Figure 3 shows this improvement.

Data procedure $1=1+6=7$

Data procedure $2=1+4=5$

\footnotetext{
${ }^{1}$ IRAN Energy Organization is a subset of TAVANIR
} 


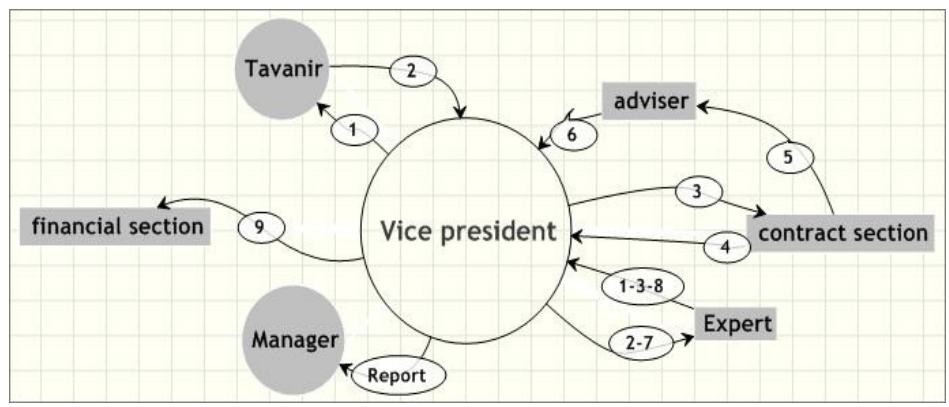

Figure 3: Improvement for data procedure in powerhouse section.

Inconsistency among the managers in Building Section of Iran efficiency organization causes delay in sending projects. We illustrate this sector situation using Mind Manager Software, in which we focus on relation delays.

Inconsistency among the managers in this branch causes delay, the delays caused by organization internal relations are 0.1 and external relations are 0.2 .

In this diagram, the project, which is designed by a related expert, should be sent to the direct manager, so that he can make the necessary decisions. Right after that, the manager gives back the design of the expert. Figure 4 illustrates it.

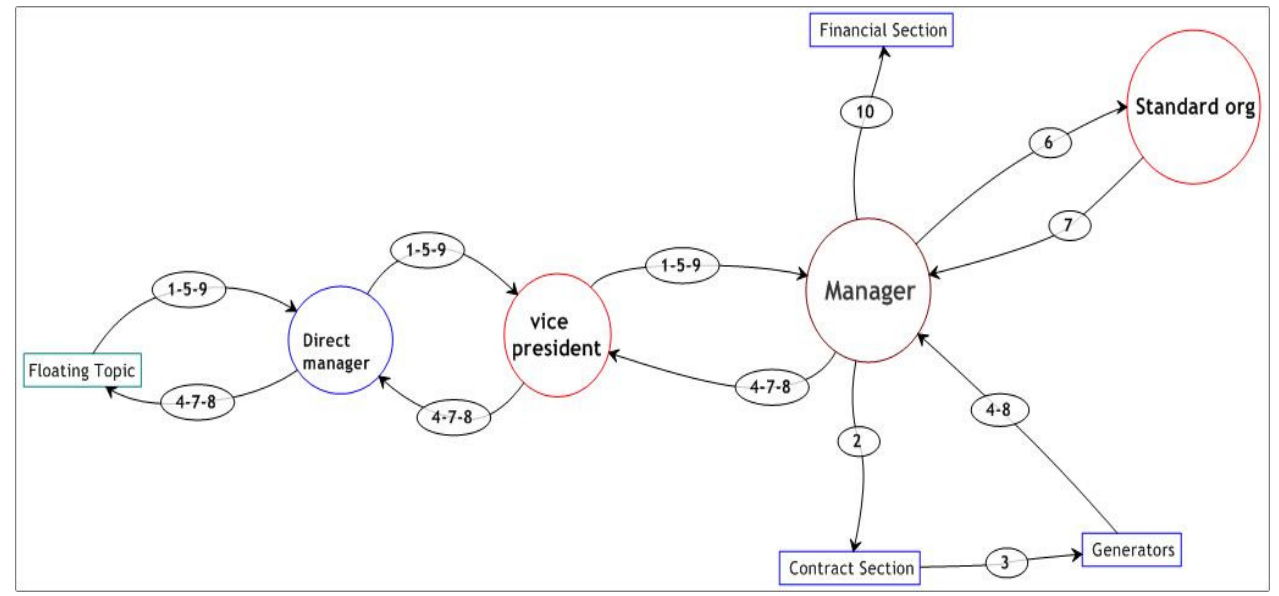

Figure4. Information flow in building section of Iran Efficiency org

After doing some corrections, the expert will send the design to the direct manager.

This process is true for vice president and the management which causes delay. We calculate the delays in specified branch (figure5). The delay equals 9 , where $9 *(0.1)=0.9$

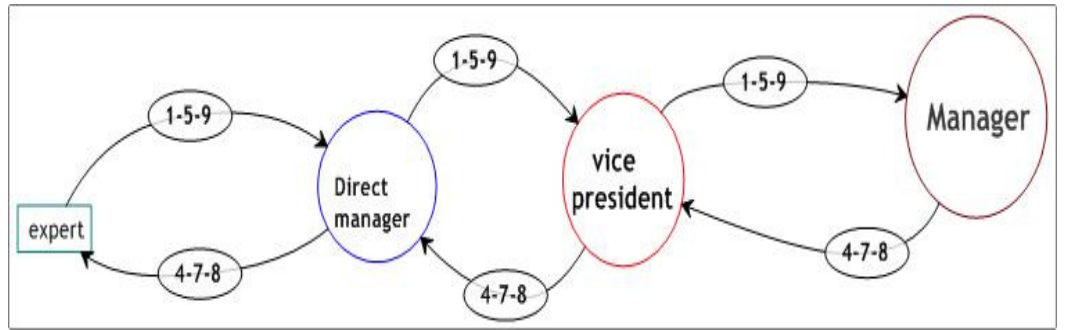

Figure5. Delay flow in one branch 
Other delays from the management are calculated according to the given values (organization internal relations equal 0.1 and external ones equal 0.2 ). This will be added to the branch delay, which equals 3.3.

Delay $=10(0.1)+2(0.2)+6(0.1)+2(0.2)+0.2+7(0.1)=3.3$

But the total delay will be: The delay caused by decision makers + delay caused by relations.

Where the delay caused by decision makers is any delay which any decision maker causes to make decision which is considered 1.

The solution for improving the delay values is convening a task group consists of expert, direct manager, vice president and the manager, in which the proposed project will be passed. So the delays caused by sending and returning the project will be eliminated (figure6).

Delay $=4(0.1)+2(0.2)+6(0.1)+2(0.2)+0.2+7(0.1)=2.7$

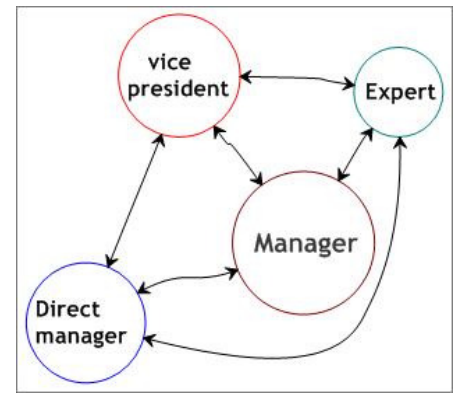

Figure6. A task group consists of expert, direct manager, vice president and the manager.

So the delay value will be 2.7 which decreased about 0.6 .

By abdicating the authority, the delay value decreases considerably.

We could reduce delay rate with FINC methodology on Iran energy efficiency organization organization. We show the result of these studies in table3. In this table we compare the current situation and improvement situation for two separate sections of Iran energy efficiency organization.

Table3. Summary results of Delay reduction in Iran energy efficiency organization

\begin{tabular}{|c|c|c|c|c|}
\hline \multicolumn{2}{|c|}{ Section } & $\begin{array}{c}\text { Current } \\
\text { Situation }\end{array}$ & $\begin{array}{c}\text { Improvement } \\
\text { situation }\end{array}$ & $\begin{array}{c}\text { Delay rate } \\
\text { decrease }\end{array}$ \\
\hline \multirow{2}{*}{$\begin{array}{c}\text { Power } \\
\text { plant }\end{array}$} & data procedure1 & 13 & 7 & 6 \\
\cline { 2 - 5 } & data procedure2 & 9 & 5 & 4 \\
\hline \multicolumn{2}{|c|}{ Building } & 3.3 & 2.7 & 0.6 \\
\hline
\end{tabular}

Two sections on Iran energy efficiency organization is based on FINC methodology but for improving them, we consider two separate demotions of them as we can consolidate them together and reduce delay more.

We also test reduction of delay rate in real world for building section on Iran energy efficiency organization and obtain desired result. This result has been shown in table4. 
Table4. Real result of delay reduction in building section of Iran energy efficiency organization

\begin{tabular}{|l|c|c|}
\hline \multirow{2}{*}{ Building section } & Previous method & New method \\
\cline { 2 - 3 } & 5 day & 2 day \\
\hline
\end{tabular}

\section{Conclusion \& FUTURE WORK}

In this paper, we have presented how FINC methodology can be used for business organization. The application of FINC methodology is in military but we could change the application for Iran energy efficiency organization as an instance of business organization. By using FINC methodology in Iran energy efficiency organization, we could find the parts and reasons causing delays in information flows. We could calculate these delay values. Delay values in this organization were estimated based on total delays caused by decision maker (intelligence nodes) and project hierarchy movement. Then we found solutions for reduction these delays times.

So, we can use FINC methodology for every business organization. We considered nodes and relations for delay reduction, but we can focus on projects that reach in parallel to the decision nodes. We can improve FINC methodology for high priority projects in parallel processing.

\section{REFERENCES}

[1] Rajive Dewan, Abraham Seidmann, Zhiping Walter, Workflow Optimization through Task Redesign in Business Information Processes, IEEE conferences, 2010

[2] Alemu Moges Belay,Design for Manufacturability and Concurrent Engineering for product Development,World Academy of Science,Engineering and Technology, 2009

[3] Albert Munoz, Michael D.Clements, Disrruptions in Information Flow: A Revenue Costing Supply Chain Dilemma, Journal of Thretical and Applied Electronic Commerce Research, 2008, pp32-36

[4] QingHuang, Amardeep Thind, Jonathan F Dreyer and Gregory S Zaric, The impact of delays to admission from the emergency department on inpatient outcomes, Huang et al. BMC Emergency Medicine 2010

[5] Stanley Wasserman and Katherine Faust. Social Network Analysis: Methods and Applications, Cambridge University Press, 1994.

[6] wikipepia, social network analysis, http://en.wikipedia.org/wiki/Social_network

[7] Kate Ehrlich1 and Inga Carboni2, Inside Social Network Analysis, Boston College.

[8] Jordi Sabater, Carles Sierra, Reputation and Social Network Analysis in MultiAgent Systems , IIIA Artificial Intelligence Research Institute ,CSIC Spanish Scientific Research Council

[9] Anthony Dekker, Social Network Analysis in Military Headquarters using CAVALIER , C3 Research Centre ,Defence Science Technology Organisation (DSTO), Fernhill Park, Department of Defence ,Canberra ACT 2600, Australia,2000

[10] Anthony H. Dekker , Appliying Social Analysis Concepts to Military C4ISR Architecture, DSTO C3 Reasearch Center, Fernhill Park, Department of Defence, Canberra.ACT Australia ,2002

[11] Anthony H. Dekker, C4ISR, THE FINC METHODOLOGY, AND OPERATIONS IN URBAN TERRAIN , JOURNAL OF BATTLEFIELD TECHNOLOGY VOL 8, NO 1, MARCH 2005.

[12] Anthony H. Dekker, Applying the FINC (Force, Intelligence, Networking and C2) Methodology to the Land Environment, Defence Systems Analysis Division, Information Sciences Labora 